\title{
Disruption of a glycogen-branching enzyme gene, glgB, specifically affects the sporulation- associated phase of glycogen accumulation in Streptomyces aureofaciens
}

\author{
Dagmar Homerová, ${ }^{1}$ Oldřich Benada, ${ }^{2}$ Olga Kofroňová, ${ }^{2}$ \\ Bronislava Řežuchová ${ }^{1}$ and Ján Kormanec ${ }^{1}$
}

1 Institute of Molecular Biology, Slovak Academy of Sciences, 84251

Bratislava, Slovak Republic

2 Institute of Microbiology, Academy of Sciences of the Czech Republic,

Videnska 1083, 14220

Prague 4, Czech Republic

\author{
Author for correspondence: Ján Kormanec. Tel: +427378 2432. Fax: +427372316. \\ e-mail:umbijkor@savba.sk
}

\begin{abstract}
In the course of Streptomyces differentiation, glycogen is accumulated in two discrete phases: in substrate hyphae that undergo aerial mycelium formation (phase I), and during septation of aerial hyphae (phase II). We have disrupted a previously identified gene, glgB, encoding a putative glycogen-branching enzyme in Streptomyces aureofaciens. Disruption of the gene had no profound effect on sporulation. However, the amount of glycogen-like polysaccharides, compared to wild-type (WT) $S$. aureofaciens, decreased in the late stage of differentiation of the glgB-disrupted strain. Absorption spectra of polysaccharides extracted from the WT and glgB-disrupted strains have shown the presence of glycogen in both strains in the first stage of differentiation (aerial mycelium formation), and unbranched glucan was detected in the glgBdisrupted strain in the late stage of differentiation. The results were confirmed by electron microscopy after silver proteinate staining of glycogen granules. Two distinct glycogen-branching enzymes, which had temporally different expression during differentiation, were detected in WT S. aureofaciens. The absence of this enzyme activity in the late stage of differentiation in the g/gB mutant suggests that the product of the glgB gene is responsible for phase II glycogen accumulation.
\end{abstract}

Keywords: Streptomyces aureofaciens, differentiation, glycogen, glycogen-branching enzyme, $g \lg B$

\section{INTRODUCTION}

Streptomycetes are Gram-positive mycelial soil bacteria that undergo a complex process of morphological differentiation. Germination of spores on solid media leads to the formation of a vegetative (substrate) mycelium consisting of a network of branching, multinucleoidal hyphae. In response to unknown signal(s), which may involve nutrient limitation, the substrate mycelium gives rise to an aerial mycelium consisting of upwardly protruding hyphae that impart a characteristically fuzzy, white appearance to the colonies. The aerial hyphae undergo septation to form chains of uninucleate cells, which metamorphose into pigmented spores that impart a species-specific colour to the colonies. Coincident with morphological differentiation, streptomycetes produce a

Abbreviations: EM, electron microscopy; WT, wild-type. variety of biologically active secondary metabolites, including the majority of known antibiotics (Champness \& Chater, 1994; Chater, 1993).

Glycogen (a large polymer of 1,4- $\alpha$-linked glucose residues with 1,6- $\alpha$-linked branches) is accumulated in many bacteria as a storage material providing nutrient supply for endogenous metabolism and possibly for survival under starvation conditions. Its biosynthesis involves three enzymes: ADPglucose pyrophosphorylase (EC 2.7.7.27), glycogen synthase (EC 2.4.1.21) and the branching enzyme (1,4- $\alpha$-D-glucan: $1,4-\alpha$-D-glucan 6 glycosyltransferase; EC 2.4.1.18), products of the $g l g C$, $g \lg A$ and $g \lg B$ genes (Preiss \& Romeo, 1989). Glycogen has been detected in several Streptomyces spp. (Braña et al., 1982; Ranade \& Vining, 1993; Plaskitt \& Chater, 1995). In the course of Streptomyces differentiation, glycogen accumulates in two temporally and spatially distinct phases (Braña et al., 1980, 1986; Plaskitt \& Chater, 1995). 
Phase I takes place in substrate hyphae, in the region from which aerial hyphae emerge, and phase II occurs in the tips of aerial hyphae during septation into spores. These observations suggest that glycogen accumulation and degradation may play a role in morphological differentiation of streptomycetes. It seems likely that phase I glycogen is used as a nutrient source for the aerial mycelium formation, and phase II glycogen is used for spore maturation (Braña et al., 1986; Chater, 1989; Plaskitt \& Chater, 1995).

The gene $g \lg B$, encoding a putative glycogen-branching enzyme which catalyses the last step in glycogen formation, was identified in Streptomyces aureofaciens CCM3239 (Homerová \& Kormanec, 1994). To prove that the gene actually encodes the glycogen-branching enzyme, and to elucidate its role in differentiation, we have disrupted the gene in the $S$. aureofaciens chromosome.

\section{METHODS}

Bacterial strains and culture conditions. $S$. aureofaciens CCM3239 wild-type (WT) (ATCC 10762) was from the Czechoslovak Collection of Microorganisms, Brno, Czech Republic. Escbericbia coli SURE (Stratagene) was used in cloning experiments. E. coli JM110 (Yanisch-Perron et al., 1985) was used for preparation of dam and $\mathrm{dcm}^{-}$plasmid DNA. E. coli plasmid pBluescript II SK $(+)$ (Stratagene) was used for cloning experiments. For DNA isolation and protoplast preparation, S. aureofaciens was cultured to late-exponential phase $(24 \mathrm{~h})$ in liquid TSB medium (Hopwood et al., 1985) containing $1 \%$ $(\mathrm{w} / \mathrm{v})$ maltose and $0.5 \%(\mathrm{w} / \mathrm{v})$ glycine in a $500 \mathrm{ml}$ baffled flask as described by Kormanec et al. (1993). Transformation of $S$. aureofaciens was carried out as described by Kormanec et al. (1993). For preparation of surface-grown cultures, $10^{8}$ spores of WT or distupted $S$. aureofaciens strains were spread on sterile cellophane membranes on solid Bennet medium (Horinouchi $e t$ al., 1983) and grown to the appropriate phase of development. Conditions for $E$. coli growth and transformation were as described by Ausubel et al. (1987).

DNA isolation and Southern blot hybridization. E. coli plasmid DNA was isolated as described by Ausubel et al. (1987). Chromosomal DNA from WT and disrupted S. aureofaciens strains was isolated according to Hopwood et al. (1985). Chromosomal DNA $(1 \mu \mathrm{g})$ was digested with the appropriate restriction endonuclease, separated by electrophoresis in a $0.8 \%$ $(\mathrm{w} / \mathrm{v})$ agarose gel in TBE $(1 \times$ TBE is $89 \mathrm{mM}$ Tris, $89 \mathrm{mM}$ boric acid, $2 \mathrm{mM}$ EDTA, pH 8.3), and transferred to Hybond$\mathrm{N}$ (Amersham) as described by Ausubel et al. (1987). The membrane was then hybridized with a random primed $[\alpha-$ $\left.{ }^{32} \mathrm{P}\right] \mathrm{dCTP}$-labelled DNA probe at $45^{\circ} \mathrm{C}$ in $50 \%(\mathrm{v} / \mathrm{v})$ formamide as described by Ausubel et al. (1987). High-stringency hybridization was done under these standard conditions, with the last post-hybridization wash at $65^{\circ} \mathrm{C}$ in $0.1 \times \mathrm{SSC}(1 \times \mathrm{SSC}$ is $0 \cdot 15 \mathrm{M}$ sodium chloride, $0.015 \mathrm{M}$ sodium citrate), $0 \cdot 1 \%(\mathrm{w} / \mathrm{v})$ SDS; low-stringency hybridization was done at $37^{\circ} \mathrm{C}$ in $50 \%$ $(\mathrm{v} / \mathrm{v})$ formamide, with the last post-hybridization wash at $50^{\circ} \mathrm{C}$ in $0.1 \times \mathrm{SSC}, 0.1 \%(\mathrm{w} / \mathrm{v}) \mathrm{SDS}$.

Recombinant DNA techniques. All DNA manipulations in $E$. coli were performed as described by Ausubel et al. (1987). DNA fragments were isolated from agarose gels with Geneclean (BIO101).

Disruption of the $g / g B$ gene. Plasmid pRPO6-26C contained a 2600 bp Sau3AI-PstI $S$. aureofaciens chromosomal fragment, comprising the full-length $g \lg B$ gene with flanking regions
(Homerová \& Kormanec, 1994), in BamHI-PstI-digested pBluescript $\mathrm{SK}(+)$. Plasmid pRPO6-26F, used for disruption of the $g \lg B$ gene, was prepared by replacing a 570 bp $M l u \mathrm{I}-S_{a} / \mathrm{I}$ glgB internal fragment in pRPO6-26C by a 1050 bp $S m a I$ fragment of pFK41 (Kormanec et al., 1993) containing the $t s r$ gene (a gene encoding thiostrepton resistance) of Streptomyces azureus. The resulting plasmid was used to transform $S$. aureofaciens protoplasts by the recently described method of Kormanec et al. (1993). Correct replacement of WT glgB by the glgB-disrupted allele was checked by Southern blot hybridization.

Analytical procedures. All determinations were done in triplicate using three independent plates for each time point over the course of differentiation. Extraction and determination of polysaccharides were done as described by Braña et al. (1982), except that the amount of polysaccharides was expressed as $\mu \mathrm{g}$ polysaccharides (mg protein $)^{-1}$ in the cell extract. This expression is more precise since it takes into account only disrupted cells. The protein concentration was determined by the method of Bradford (1976). For dry cell weight determination, mycelium from three plates was removed and dried at $100{ }^{\circ} \mathrm{C}$ to constant weight. The iodine-polysaccharide complexes were prepared as described by Braña et al. (1982), and the absorption spectra of the complexes were measured in a Beckman DU 20 recording spectrophotometer. The absorption spectra of iodine-polysaccharide complexes were measured in aqueous solutions and in the presence of $\left(\mathrm{NH}_{4}\right)_{2} \mathrm{SO}_{4}$ to half saturation. For comparison, the spectra of well-characterized polysaccharides glycogen, amylopectin and amylose were determined under the same conditions.

Protein extraction. After harvesting from plates, cells were washed in extraction buffer $(50 \mathrm{mM}$ Tris $/ \mathrm{HCl}, \mathrm{pH} 7 \cdot 0 ; 1 \mathrm{mM}$ EDTA; $10 \mathrm{mM}$ mercaptoethanol; $0.2 \mathrm{mM}$ PMSF) at $4{ }^{\circ} \mathrm{C}$. All other procedures were done at this temperature. Cells $(1 \mathrm{~g}$ wet weight) were suspended in $2 \mathrm{ml}$ extraction buffer and sonicated at $20 \mathrm{~W}$ on ice with six bursts of $15 \mathrm{~s}$, allowing $20 \mathrm{~s}$ in between for cooling. The suspension was centrifuged at $100000 \mathrm{~g}$ for $1 \mathrm{~h}$, yielding the S100 (supernatant) fraction.

Staining to detect glycogen-branching enzyme activity. Glycogen-branching enzyme activity was detected after native starch-PAGE as described by Rammesmayer \& Praznik (1992). Samples of $\mathrm{S} 100$ fractions $(10 \mu \mathrm{g}$ protein) were loaded on $15 \%$ (w/v) acrylamide/1\% (w/v) starch gels and further treated as described by Rammesmayer \& Praznik (1992). The zones of glycogen-branching enzyme activity appeared as sharp red bands on the blue-stained background.

Electron microscopy (EM). At various times of growth, samples of mycelium were removed from cellophane and fixed in 3\% $(\mathrm{w} / \mathrm{v})$ glutaraldehyde in $0.1 \mathrm{M}$ sodium cacodylate at room temperature (Gordon et al., 1963). Samples were dehydrated with ethanol and acetone, and embedded in Vestopal. Thin sections were stained for polysaccharides according to Thiery (1967). Control samples were prepared in the same manner except that they were stained in periodic acid. The general morphology of mycelium samples was checked on samples fixed according to Kellenberger $e$ t al. (1958) and stained according to Reynolds (1963). Electron micrographs were taken with a Philips CM-12 electron microscope.

\section{RESULTS}

\section{Disruption of the $g / g B$ gene}

Based on the high amino acid sequence similarity, the $g \lg B$ gene that we have cloned (Homerová \& Kormanec, 1994) 

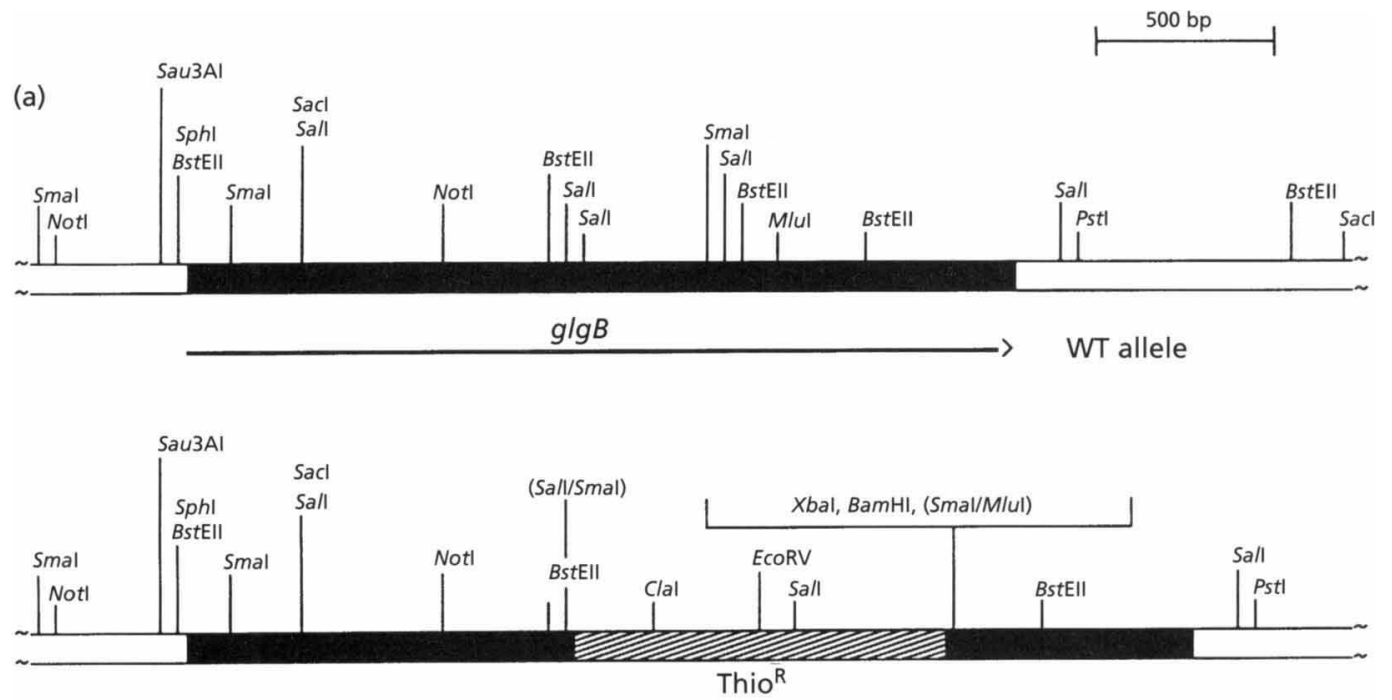

Probe 1

Disrupted allele

Probe 2

(b)

Probe 2

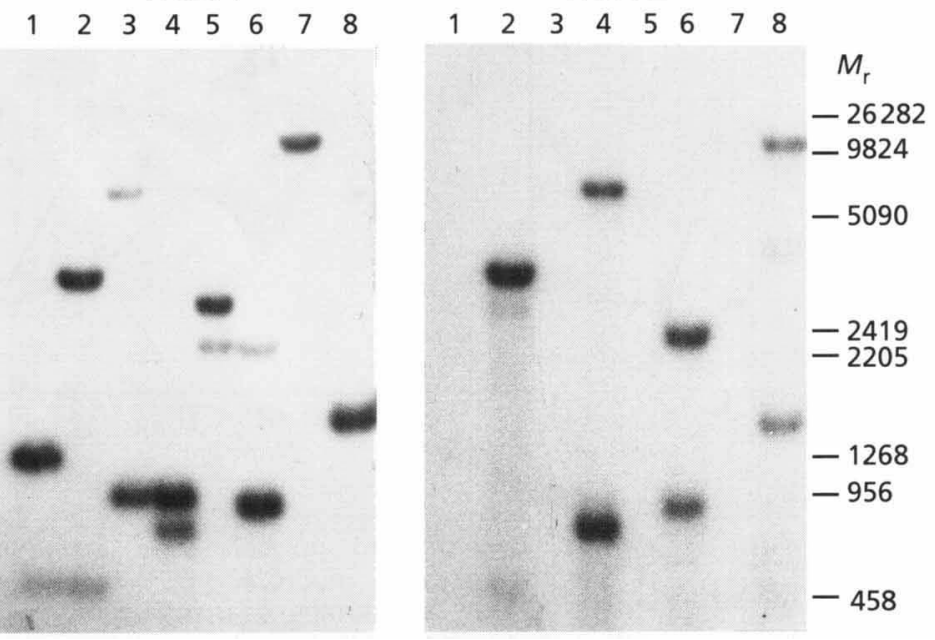

Fig. 1. (a) Chromosomal DNA comprising $g / g B$ of S. aureofaciens CCM3239 WT strain and the strain disrupted via double crossover. The black bars below the maps represent probes used for Southern hybridization analysis. Probe 1 is a 1060 bp BstEll fragment comprising the upstream part of $\mathrm{g} / \mathrm{gB}$; probe 2 is a $1050 \mathrm{bp}$ Smal fragment of pFK41 (Kormanec et al., 1993) containing the $t s r$ gene. Restriction sites relevant to the Southern hybridization experiment are indicated. Thio ${ }^{R}$. thiostrepton resistance. (b) Southern hybridization analysis of chromosomal DNA from the gene replacement experiments. Experimental details are in Methods. Lanes: 1, Smal-digested WT S. aureofaciens CCM3239 DNA; 2, Smaldigested DNA from the g/gB-disrupted strain; 3, EcoRV- and Notl-digested WT DNA; 4, EcoRV- and Notl-digested disrupted DNA; 5, Sacl-and Clal-digested WT DNA; 6, SaCl- and Clal-digested disrupted DNA; 7, Sphl- and EcoRV-digested WT DNA; 8, Sphl- and EcoRV-digested disrupted DNA. The Southern blot was probed with probe 1 comprising part of $g / g B$. The same blot was treated to remove radioactive probe 1 as described in Ausubel et al. (1987) and probed with probe 2 comprising the tsr gene under the same conditions. Mlul-digested $\lambda$ DNA was used as the $M_{\mathrm{r}}$ standards.

may encode a glycogen-branching enzyme. To prove this, we attempted to disrupt the $S$. aureofaciens chromosomal allele of $g \lg B$. To disrupt the gene, we replaced the WT $\operatorname{glg} B$ chromosomal allele by a disrupted one with an inserted $t s r$ gene (Fig. 1a). The tsr marker replaced the sequences encoding regions 3, 4 and 5 that were assumed to constitute the active site of branching enzymes
(Homerová \& Kormanec, 1994 ; MacGregor \& Svensson, 1989 ), and should result in a null mutation. The resulting plasmid, pRPO6-26F, was used to transform $S$. aureofaciens. Three thiostrepton-resistant transformants were chosen and integration of pRPO6-26F into the chromosome was confirmed by Southern blot hybridization. In one case, the integration occurred through double cross- 


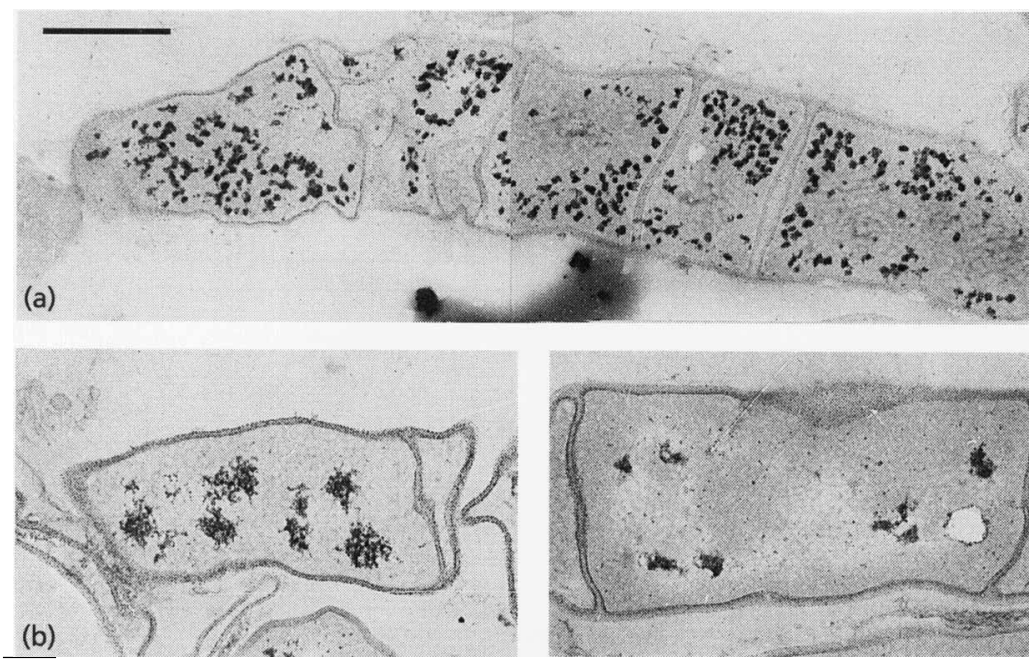

Fig. 2. Phase II polysaccharide deposition in the $S$. aureofaciens WT and $g / g B$-disrupted strains. Thin sections of colonies of $S$. aureofaciens WT (a) and its glgB disruptant (b) grown for $47 \mathrm{~h}$ were stained for polysaccharide deposits and examined by transmission EM. Aerial hyphae undergoing septation contained many glycogen granules in the WT strain (a), whereas large irregular bodies of unbranched polysaccharides appeared in the $g / g B$ disruptant. Bar, $0.5 \mu \mathrm{m}$.

over, resulting in the replacement of the W'T $g \lg B$ gene by the disrupted allele (Fig. 1b).

\section{Disruption of $g l g B$ affects the morphology of the stage II glycogen deposits}

The $g l g B$-disrupted strain resulting from a double recombination event was viable and stable. Growth in liquid TSB medium and minimal NMP medium (Hopwood et al., 1985) was comparable with the WT strain. On solid Bennet medium, the disrupted and the WT strains produced comparable aerial mycelium and spores. Light microscopic and EM analysis showed no obvious morphological defects. However, EM of ultrathin sections of colonies grown on solid medium to a different stage of differentiation and stained with silver proteinate (Thiery, 1967) showed differences in the morphology of polysaccharide granules in the $g \lg B$ disrupted strain, compared to the WT strain. As previously described for other Streptomyces strains (Braña et al., 1982, 1986; Plaskitt \& Chater, 1995), S. aureofaciens accumulated glycogen granules in two different stages during differentiation. Undifferentiated young substrate mycelium $(12 \mathrm{~h})$ lacked any polysaccharide granules. The granules appeared in those parts of the substrate mycelium from which aerial branches emerge, at the time of aerial mycelium formation $(19 \mathrm{~h})$ (data not shown). This accumulation was termed phase I (Plaskitt \& Chater, 1995). After $30 \mathrm{~h}$ growth, a well-developed aerial mycelium could be observed that was free of polysaccharide granules. In the sporulating hyphae undergoing septation (after $47 \mathrm{~h}$ cultivation), new deposits of polysaccharide granules (phase II) were visible at the tips of the aerial mycelium. In contrast to Streptomyces antibioticus (Braña et al., 1986), and similar to Streptomyces coelicolor (Plaskitt \& Chater, 1995), the granules were visible only in those parts of sporulating hyphae that underwent the final septation (Fig. 2a). Similarly to results from other Streptomyces strains (Braña et al., 1986; Plaskitt \& Chater, 1995), polysaccharide granules decreased during spore maturation, and were absent in mature spores (data not shown).

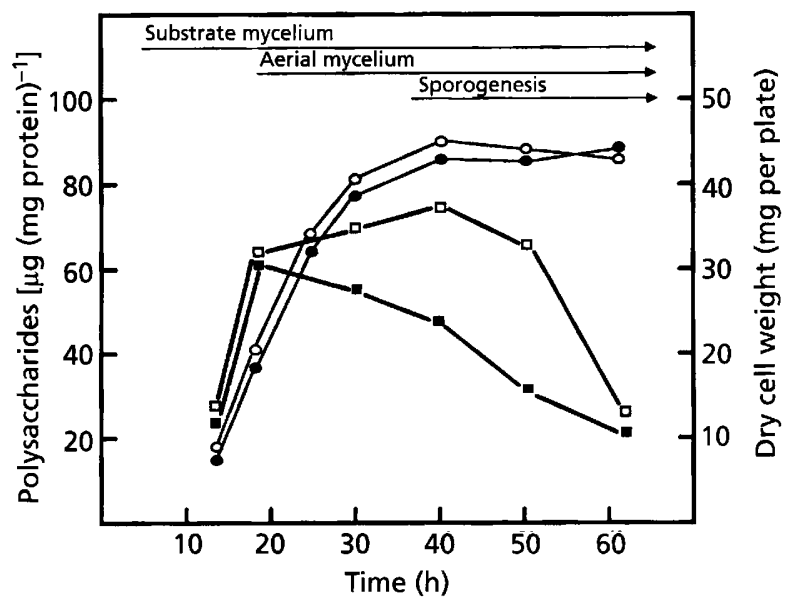

Fig. 3. Growth and polysaccharide accumulation during differentiation of $S$. aureofaciens WT and g/gB-disrupted strains. Strains were grown on solid Bennet medium covered with a cellophane membrane. The mycelium was removed from the plates and the dry cell weight of the WT $(O)$ and glgBdisrupted strains (O) was determined. Accumulation of polysaccharides of the WT ( $\square$ ) and glgB-disrupted strains ( $\square$ ) was measured in mycelium homogenized as described in Methods. The different phases of differentiation are indicated at the top of the figure. The results are means of three determinations.

In the $g l g B$-disrupted $S$. aureofaciens strain, polysaccharide granules were clearly visible in substrate mycelium (phase I), similar to the WT strain (data not shown). However, in the sporulating hyphae, the polysaccharide deposits of phase II had a conspicuously changed appearance. Instead of small dispersed granules, immature spores contained very large irregular bodies (Fig. 2b). The appearance of the deposits was similar to one class of E. coliglgB mutant containing unbranched 1,4- $\alpha$-linked glucan deposits (Lares et al., 1974). The results suggest that the disruption of the $g \lg B$ gene in $S$. aureofaciens affects only phase II accumulation of glycogen. 

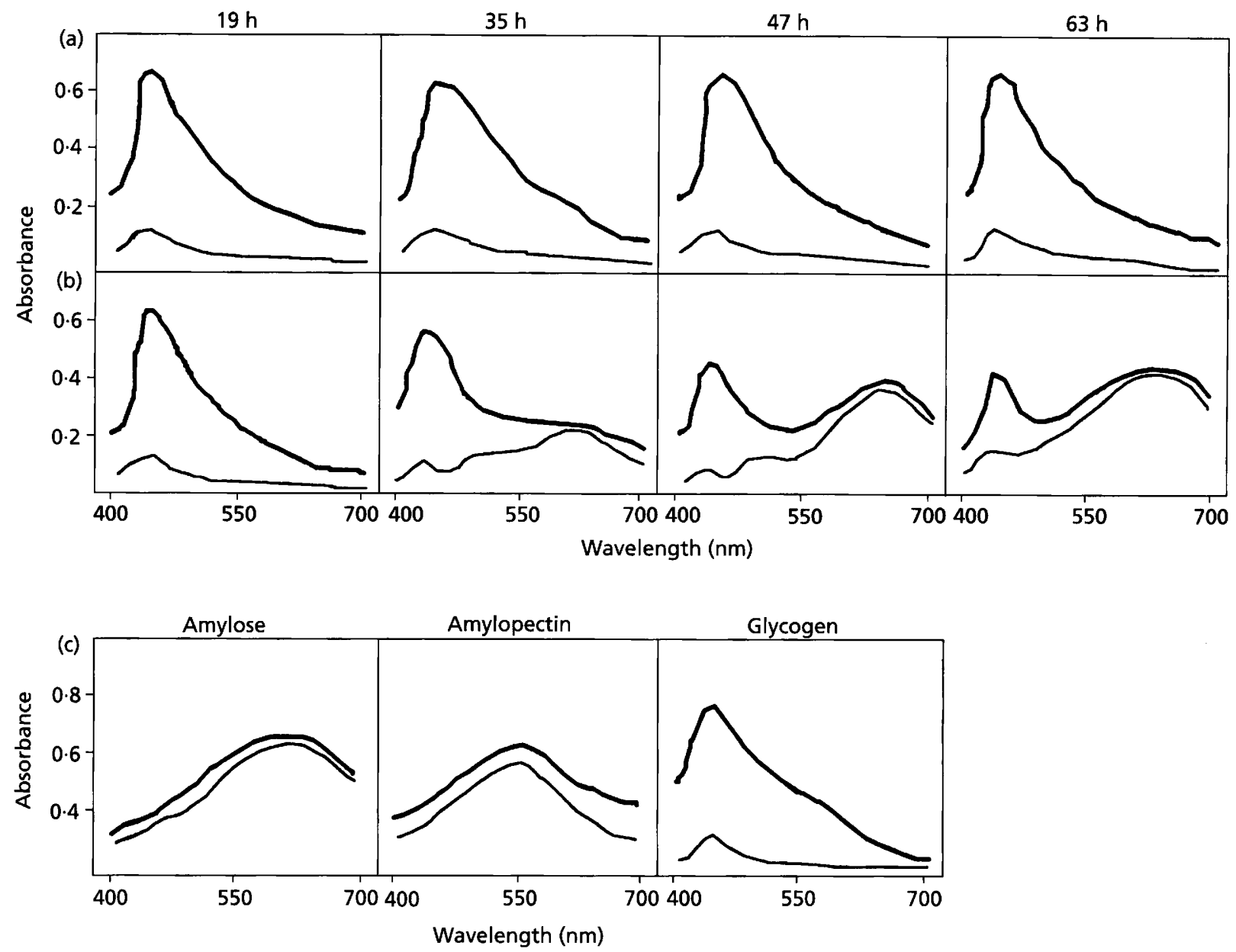

Fig. 4. lodine absorption spectra of polysaccharides extracted from different stages of differentiation of $S$. aureofaciens WT (a) and glgB-disrupted strains (b). Strains were grown on solid Bennet medium covered with a cellophane membrane. At the time indicated at the top of the figure the mycelium was removed from the plates and treated as described in Methods. Absorption spectra of the well-characterized polysaccharides potato amylose and amylopectin (Koch-Light) and glycogen from mussels (Boehringer Mannheim) were determined under the same conditions $(c)$. Thin lines indicate spectra measured in aqueous solution. Thick lines indicate spectra measured in $50 \%(\mathrm{w} / \mathrm{v})$ saturated ammonium sulphate solutions.

\section{Analysis of the polysaccharides in the glgB-disrupted strain during differentiation}

Based on the results above, it seems likely that the amount of polysaccharide deposits in the glgB-disrupted strain decreases during sporulation. Therefore, the amount of polysaccharides during colony differentiation in WT and glgB-disrupted $S$. aureofaciens strains was measured. The time course was similar in both strains during substrate mycelium formation and at the beginning of aerial mycelium formation (Fig. 3). However, during sporogenesis, accumulation was different. In the WT strain, the amount of polysaccharides increased, reaching a maximum at $40 \mathrm{~h}$, which approximately corresponds to the onset of sporogenesis; a gradual decrease followed as maturation of spores proceeded. The course was similar to glycogen accumulation in S. antibioticus (Braña et al., 1986). In the $g \lg B$-disrupted $S$. aureofaciens strain, the amount of polysaccharides decreased earlier than in the
WT strain; the maximum level was found at the beginning of aerial mycelium formation $(19 \mathrm{~h})$. The results show that the disruption of $g l g B$ also affects the amount of polysaccharides produced in later stages of $S$. aureofaciens differentiation.

The qualitative characteristics of the polysaccharides were investigated, following extraction from mycelium grown to various stages of differentiation. Iodine complexes of glycogen have a wavelength of maximal absorbance $\left(\lambda_{\max }\right)$ of about $420 \mathrm{~nm}$, depending upon source; the $\lambda_{\max }$ of amylopectin (partially branched polysaccharide) is between 530 and $550 \mathrm{~nm}$, and that of amylose (unbranched polysaccharide) is more than $600 \mathrm{~nm}$ (Archibald et al., 1961). The results showed (Fig. 4) that polysaccharides isolated from substrate mycelium of both strains at the beginning of aerial mycelium formation $(19 \mathrm{~h}$ ) have very similar absorption spectra, with a $\lambda_{\max }$ of $420 \mathrm{~nm}$. This value corresponds to the glycogen-like polysaccharides 


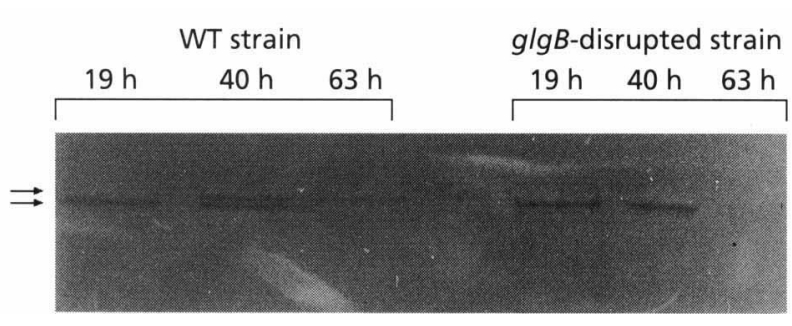

Fig. 5. Specific staining for glycogen-branching enzyme activity after native starch-PAGE (Rammesmayer \& Praznik, 1992). Samples of S100 fractions from S. aureofaciens WT and glgBdisrupted strains $(10 \mu \mathrm{g}$ protein), grown on solid Bennet medium to different stages of differentiation, were loaded on $15 \%(\mathrm{w} / \mathrm{v})$ acrylamide/1\% (w/v) starch gels and further treated as described in Methods. The beginning of aerial mycelium formation corresponds to $19 \mathrm{~h}$, the beginning of sporulation corresponds to $40 \mathrm{~h}$, and almost mature spore formation corresponds to $63 \mathrm{~h}$. The zones of glycogen-branching enzyme activity are indicated by arrows.

with high branching. This glycogen may correspond to phase I polysaccharide deposits visible in EM stained sections in both strains. Differences in the spectra appeared after $35 \mathrm{~h}$ growth, corresponding to welldeveloped aerial mycelium, where the $\lambda_{\max }$ value of the glg $B$-disrupted strain shifted to the higher wavelength $(600 \mathrm{~nm})$, which corresponds to unbranched polysaccharides (Fig. 4b). The shift in the $\lambda_{\max }$ in the $g \lg B$ disrupted strain is pronounced with polysaccharides isolated from later phases of differentiation, while absorption spectra of polysaccharides from the WT strain are similar in all stages of differentiation, and correspond to glycogen-like polysaccharides (Fig. 4a). The marked increase in the absorbance maximum of iodinepolysaccharide complexes in the presence of ammonium sulphate differentiates glycogen from the less-branched amylopectins (Archibald et al., 1961). Therefore, the same absorption spectra were measured in the presence of ammonium sulphate to half saturation. As shown in Fig. 4(a), only glycogen is present in all stages of differentiation of the WT strain (absorbance maximum increased sevenfold in the presence of ammonium sulphate), while in the glgB-disrupted strain (Fig. 4b) glycogen is present in earlier stages of differentiation as phase I glycogen (similar increase in absorbance maximum to the WT strain), and in the course of differentiation the amount of the glycogen decreases and unbranched polysaccharides are produced (only a negligible increase of $A_{\max }$ was detected). The results show that the disruption of $\operatorname{glg} B$ resulted in the presence of unbranched polysaccharides in later stages of differentiation. In the early stages, the glycogen-like polysaccharides are present in the glgB-disrupted strain, similar to the WT strain.

\section{Detection of the glycogen-branching enzymes during differentiation in WT and g/gB-disrupted strains}

The previous results suggested the presence of two glycogen-branching enzymes in $S$. aureofaciens, each being responsible for formation of glycogen in a distinct developmental stage and cell compartment: in substrate mycelium at the time of aerial mycelium formation (phase I) and in sporulating aerial hyphae (phase II). To prove this, the cell extracts from WT and $g l g B$-disrupted strains, cultivated on solid Bennet medium to different stages of differentiation, were analysed by native starch-PAGE, and specifically stained for glycogen-branching enzyme activity. This method is based on native electrophoretic division of proteins in the presence of starch, followed by reaction of starch-utilizing enzymes with the starch present in the gel. Starch forms a blue background in the gel after staining, $\alpha$-amylase gives a transparent band corresponding to utilized starch, and a red band corresponds to glycogen, formed by the migration of a glycogen-branching enzyme to this position (Rammesmayer \& Praznik, 1992). As shown in Fig. 5, two distinct glycogen-branching enzymes are present in the WT $S$. aureofaciens strain. The enzyme with faster mobility is present only in the early stages of differentiation (19 h, corresponding to aerial mycelium formation), while both forms of enzyme are present in the $40 \mathrm{~h}$ sample (corresponding to aerial mycelium approximately at the onset of sporulation). Later in sporulation, only the slower migrating form of the enzyme is present. In the $g l g B$-disrupted strain, only the faster migrating form of the enzyme is present, and only in the early stages of differentiation. The slower migrating form was missing in these samples. The results indicate the presence in $S$. aureofaciens of two glycogen-branching enzymes with different electrophoretic mobilities and differentially regulated expression during differentiation of $S$. aureofaciens. The disruption of $g l g B$ affects only the later form of the enzyme, responsible for formation of phase II glycogen.

\section{DISCUSSION}

In Streptomyces, two phases of glycogen accumulation were detected during differentiation (Braña et al., 1986; Plaskitt \& Chater, 1995). This indicates two possibilities: (1) there is one set of structural genes for glycogen accumulation which is differentially (temporally and spatially) regulated during differentiation; (2) there are two sets of structural genes, each one responsible for a distinct phase of glycogen accumulation. The results of our study of $g \lg B$, encoding the enzyme which is responsible for the last step in glycogen formation, give preference to the second alternative. This assumption is based on the following results. (1) Silver proteinate staining of polysaccharides in the glgB-disrupted strain showed normal phase I glycogen accumulation and a changed appearance of phase II glycogen accumulation. (2) The course of polysaccharide accumulation during differentiation in the disrupted strain, as compared to WT strain, was changed only in the later stages of the process, approximately corresponding to the onset of sporulation. (3) Qualitative analysis of polysaccharides revealed that the $g \lg B$-disrupted strain forms glycogen during earlier stages of differentiation, and later, during sporulation, unbranched glucans are formed. (4) Staining for the activity of glycogen-branching enzymes in WT and disrupted strains revealed two distinct enzymes; one 
(expressed later in differentiation) is missing in extracts of the $g \lg B$-disrupted strain. The results of the study clearly show that the $g \lg B$ gene identified in $S$. aureofaciens (Homerová \& Kormanec, 1994) encodes a glycogenbranching enzyme which is necessary for phase II glycogen formation in sporulating aerial hyphae. However, disruption of the $S$. aureofaciens glgB gene had no obvious effect on sporulation. It seems likely that the deposits of unbranched glucans formed in the $g l g B$ disrupted strain are sufficient for spore maturation.

The results also indirectly suggest the presence of a second $g \lg B$ gene in $S$. aureofaciens, encoding a glycogenbranching enzyme responsible for phase I glycogen accumulation. Hybridization experiments with the cloned glgB gene as a probe at very low stringency (corresponding to about $50 \%$ nucleotide identity) revealed only very faint additional bands, suggesting low similarity between these genes. This was striking, since, under the same conditions, clear signals corresponding to two putative $g \lg B$ genes in the related strain, S. coelicolor A3(2), were identified (D. Homerová \& J. Kormanec, unpublished results). In fact, recent independent studies in S. coelicolor revealed two glgB genes, products of which are responsible for distinct phases of glycogen accumulation (Bruton et al., 1995). Whether other enzymes of glycogen metabolism are also duplicated in Streptomyces would be answered after the cloning and analysis of the corresponding genes.

The situation is different in other bacteria, where the enzymes or their corresponding genes, responsible for glycogen formation, have been identified and studied. In $E$. coli, only one set of genes encoding enzymes involved in glycogen metabolism is clustered on the chromosome in two adjacent operons, expression of which is positively regulated by the intracellular level of cAMP (Preiss \& Romeo, 1989). As well as this regulation, a novel gene differing from these two operons, glgS, affects glycogen synthesis (Hengge-Aronis \& Fischer, 1992). Glycogen is accumulated at the onset of sporogenesis in several sporulating bacteria (for review, see Preiss \& Romeo, 1989). However, in several Bacillus spp. only one set of genes encoding enzymes involved in glycogen metabolism, with distinct operon organization, has been identified (Kiel et al., 1991, 1992, 1994). To date, the last two identified $g \lg B$ genes, in the ruminal bacterium Butyrivibrio fibrisolvens and the cyanobacterium Synechococcus sp., also seem to be present only in one copy on the chromosome (Kiel et al., 1990; Rumbak et al., 1991).

The presence of two glgB genes in Streptomyces seems to be connected with two distinct phases of glycogen accumulation in two different 'tissues' (substrate mycelium and aerial hyphae) during cellular differentiation. This process of differentiation resembles the life cycle of several lower eukaryotes and fungi. The fungus Phycomyces blakesleeanus also appears to contain two sets of genes since, similarly to Streptomyces, two stages of glycogen accumulation were identified during differentiation into sporangiophores (Rúa et al., 1993). Likewise, two differentially controlled genes for glycogen synthase have been identified in the yeast Saccharomyces cerevisiae (Farkas et al., 1991), and during the developmental cycle of the slime mould Dictyostelium discoideum, two genes encoding glycogen phosphorylase are differentially expressed (Rogers $e t$ al., 1994). Therefore, it seems that, based on this gene duplication, Streptomyces spp. are more similar to lower eukaryotes than to bacteria. Some preliminary experiments suggest that other genes of primary metabolism are also duplicated. $S$. aureofaciens appears to have two gap genes encoding the glycolytic enzyme glyceraldehyde-3phosphate dehydrogenase (Kormanec et al., 1995). It evokes the idea of two distinct primary metabolic pathways (or only several key enzymes), each active in a distinct cellular compartment during cell differentiation. This hypothesis requires further studies, particularly on the primary metabolism genes and the spatial location of their products.

\section{ACKNOWLEDGEMENTS}

We would like to thank Mrs Renáta Knirschová and Jirina Martinkova for excellent technical assistance. We are grateful to Professor Keith Chater for helpful comments on the manuscript. This work was supported in part by Grant GA 2/1072/94 from the Slovak Academy of Sciences.

\section{REFERENCES}

Archibald, A. R., Fleming, I. D., Liddle, A. M., Manners, D. J., Mercer, G. A. \& Wright, A. (1961). $\alpha-1,4$-Glucosans. Part XI. The absorption spectra of glycogen- and amylopectin-iodine complexes. J Chem Soc 1, 11831190.

Ausubel, F. M., Brent, R., Kingston, R. E., Moore, D. O., Seidman, J. S., Smith, J. A. \& Struhl, K. (1987). Current Protocols in Molecular Biology. New York: Wiley.

Bradford, M. M. (1976). A rapid and sensitive method for the quantitation of microgram quantities of protein utilizing the principle of protein-dye binding. Anal Biocbem 72, 248-254.

Braña, A. F., Manzanal, M. B. \& Hardisson, C. (1980). Occurrence of polysaccharide granules in sporulating hyphae of Streptomyces viridochromogenes. J Bacteriol 144, 1139-1142.

Braña, A. F., Manzanal, M. B. \& Hardisson, C. (1982). Characterization of intracellular polysaccharides of Streptomyces. Can J Microbiol 28, 1320-1323.

Braña, A. F., Méndez, C., Díaz, L. A., Manzanal, M. B. \& Hardisson, C. (1986). Glycogen and trehalose accumulation during colony development in Streptomyces antibioticus. J Gen Microbiol 132, 1319-1326.

Bruton, C. J., Plaskitt, K. A. \& Chater, K. F. (1995). Tissue-specific glycogen branching isoenzymes in a multicellular procaryote, Streptomyces coelicolor A3(2). Mol Microbiol 18, 89-99.

Champness, W. C. \& Chater, K. F. (1994). The regulation and integration of antibiotic production and morphological differentiation in Streptomyces spp. In Regulation of Bacterial Differentiation, pp. 61-93. Edited by P. J. Piggot, C. P. Moran \& P. Youngman. Washington, DC: American Society for Microbiology.

Chater, K. F. (1989). Multilevel regulation of Streptomyces differentiation. Trends Genet 5, 372-377.

Chater, K. F. (1993). Genetics of differentiation in Streptomyces. Annu Rev Microbiol 47, 685-713.

Farkas, I., Hardy, T. A., Goebl, M. G. \& Roach, P. J. (1991). Two glycogen synthase isoforms in Saccharomyces cerevisiae are encoded by 
distinct genes that are differentially controlled. J Biol Chem 266, 15602-15607.

Gordon, G. B., Miller, L. R. \& Bensch, K. G. (1963). Fixation of tissue culture cells for ultrastructural cytochemistry. Exp Cell Res 31, 440-443.

Hengge-Aronis, R. \& Fischer, D. (1992). Identification and molecular analysis of $g l g S$, a novel growth-phase-regulated and rpoSdependent gene involved in glycogen synthesis in Escherichia coli. Mol Microbiol 6, 1877-1886.

Homerová, D. \& Kormanec, J. (1994). Cloning of the putative glycogen branching enzyme gene, glgB, from Streptomyces aureofaciens. Biochim Biophys Acta 1200, 334-336.

Hopwood, D. A., Bibb, M. J., Chater, K. F., Kieser, T., Bruton, C. J., Kieser, H. M., Lydiate, D. L., Smith, C. P., Ward, J. M. \& Schrempf, H. (1985). Genetic Manipulation of Streptomyces: a Laboratory Manual. Norwich: The John Innes Foundation.

Horinouchi, S., Hara, O. \& Beppu, T. (1983). Cloning of a pleiotropic gene that positively controls biosynthesis of A-factor, actinorhodin, and prodigiosin in Streptomyces coelicolor A3(2) and Streptomyces lividans. J Bacteriol 155, 1238-1248.

Kellenberger, E., Ryter, A. \& Sechaud, J. (1958). Electron microscope study of DNA-containing plasma. II. Vegetative and mature phage DNAs compared with normal bacterial nucleoid in different physiological states. J Biopbys Biochem Cytol 4, 671-674.

Kiel, J. A. K., Boels, J. M., Beldman, G. \& Venema, G. (1990). Nucleotide sequence of the Synechococcus sp. PCC7942 branching enzyme gene $(g \lg B)$ : expression in Bacillus subtilis. Gene 89, 77-84.

Kiel, J. A. K., Boels, J. M., Beldman, G. \& Venema, G. (1991). Molecular cloning and nucleotide sequence of the glycogen branching enzyme gene $(g \lg B)$ from Bacillus stearothermophilus and expression in Escherichia coli and Bacillus subtilis. Mol Gen Genet 230, 136-144.

Kiel, J. A. K., Boels, J. M., Beldman, G. \& Venema, G. (1992). The glgB gene from the thermophile Bacillus caldolyticus encodes a thermolabile branching enzyme. DNA Seq-J DNA Seq Map 3, 1-9.

Kiel, J. A. K., Boels, J. M., Beldman, G. \& Venema, G. (1994). Glycogen in Bacillus subtilis: molecular characterization of an operon encoding enzymes involved in glycogen biosynthesis and degradation. Mol Microbiol 11, 203-218.

Kormanec, J., Rezuchová, B. \& Farkasovsky, M. (1993). Optimization of Streptomyces aureofaciens transformation and disruption of the $\operatorname{brd} A$ gene encoding a homologue of the principal $\sigma$ factor. $J$ Gen Microbiol 139, 2525-2529.

Kormanec, J., Lempelová, A., Farkasovsky, M. \& Homerová, D. (1995). Cloning, sequencing and expression in Escherichia coli of a Streptomyces aureofaciens gene encoding glyceraldehyde-3-phosphate dehydrogenase. Gene 165, 77-80.
Lares, C., Frixon, C. \& Creuzet-Sigal, N. (1974). Characterization and ultrastructure of mutants of Escherichia coli deficient in $\alpha-1,4-$ glucan- $\alpha$-1,4-glucan 6-glycosyltransferase (branching enzyme). $J$ Gen Microbiol 82, 279-293.

MacGregor, E. A. \& Svensson, B. (1989). A super-secondary structure predicted to be common to several $\alpha-1,4,-D-$ glucancleaving enzymes. Biochem J 259, 145-152.

Plaskitt, K. A. \& Chater, K. F. (1995). Influences of developmental genes on localized glycogen deposition in colonies of a mycelial procaryote, Streptomyces coelicolor A3(2): a possible interface between metabolism and morphogenesis. Philos Trans R Soc Lond B 347, 105-121.

Preiss, J. \& Romeo, T. (1989). Physiology, biochemistry and genetics of bacterial glycogen synthesis. Adv Microb Pbysiol 30, 183-238.

Rammesmayer, G. \& Praznik, W. (1992). Fast and sensitive simultaneous staining of Q-enzyme, $\alpha$-amylase, R-enzyme, phosphorylase and soluble starch synthase separated by starchpolyacrylamide gel electrophoresis. J Chromatogr 623, 399-402.

Ranade, N. \& Vining, L. C. (1993). Accumulation of intracellular carbon reserves in relation to chloramphenicol biosynthesis by Streptomyces venequelae. Can J Microbiol 39, 377-383.

Reynolds, E. S. (1963). The use of lead citrate at high $\mathrm{pH}$ as an electron-opaque stain in electron microscopy. J Cell Biol 17, 208-212.

Rogers, P. V., Sucic, J. F., Yin, Y. \& Rutherford, C. L. (1994). Disruption of glycogen phosphorylase gene expression in Dictyostelium: evidence for altered glycogen metabolism and developmental coregulation of the gene products. Differentiation 56, 1-12.

Rúa, J., Busto, F., de Arriaga, D. \& Soler, J. (1993). Glycogen in Pbycomyces blakesleeanus: influence of growth conditions and nutrient limitation. J Gen Microbiol 139, 217-222.

Rumbak, E., Rawlings, D. E., Lindsey, G. D. \& Woods, D. R. (1991). Characterization of the Butyrivibrio fibrisolvens glgB gene, which encodes a glycogen-branching enzyme with starch-clearing activity. J Bacteriol 173, 6732-6741.

Thiery, J. P. (1967). Mise en évidence des polysaccharides sur coupes fines en microscopie électronique. $J$ Microse (Paris) 6, 987-1018.

Yanisch-Perron, C., Vieira, J. \& Messing, J. (1985). Improved M13 phage cloning vectors and host strains: nucleotide sequence of the M13 mp18 and pUC19 vectors. Gene 33, 103-119.

Received 11 October 1995; revised 8 January 1996; accepted 11 January 1996. 